\title{
LA EXPLOTACION GANADERA COMO ESTRATEGIA PARA FRENAR LA PERDIDA DE FERTILIDAD EN MONTAÑA
}

\author{
Federico Fillat Estaque*
}

Una de las características más aparentes de la montaña es ciertamente su variación altitudinal. En pocos kilómetros de recorrido of rece paisajes muy distintos que además adquieren mayor diversidad si los observamos a lo largo de las cuatro estaciones; espacio y tiempo ofrecen los grandes contrastes reunidos en una pequeña zona montañosa.

Los hombres que siguen habitando las montañas del mundo han adquirido unas técnicas de explotación eficaces para mantener el difícil equilibrio entre explotación y conservación de recursos. Saben que no pueden consumir el capital acumulado durante siglos y sólo extraen una pequeña renta, la imprescindible para alimentar una población poco numerosa. La actualización instantánea de una importante masa de hayas en forma de troncos maderables pone en peligro la continuidad de los manantiales que se beneficiaban del agua condensada en las ramas y hojas del árbol. El suelo desnudo sufre directamente el impacto de las gotas de lluvia y ese contínuo martilleo rompe la continuidad iniciando regatos y cárcavas que lo empujarán ladera abajo; se perderá así el capital fijo imprescindible para seguir produciendo. En este sencillo ejemplo, el agua es obtenida por precipitación horizontal y retenida en cotas elevadas que sólo abandona lentamente después de recorrer los horizontes edáficos y aflorar finalmente como manantial. En su recorrido descendente actúa como un vehículo cómodo para llevar ladera abajo los minera-

* Centro pirenaico de Biología experimental. Jaca (Huesca) 
les que lavó en la primera parte del recorrido. Esta utilización máxima del agua en cotas altas, sin que pierda de forma irremediable su energía potencial, es un principio interesante para las zonas de montaña.

E1 descenso del agua resulta seguramente el más espectacular que conoce el visitante cuando asiste a la fusión repentina de nieve en laderas empinadas. Las cascadas forman magníficas "colas de caballo" en los paredones rocosos y trasladan, en pocos segundos, enormes excedentes de agua hacia el valle. Sin embargo y de manera menos clara, esa es la trayectoria seguida por todos los cuerpos que discurren por la superficie de la Tierra, sujetos a la atracción de la gravedad. Se comprende fácilmente que el montañés haya agudizado el ingenio para retener cerca de sus pueblos las laderas de tierra y grava que recibió de las cumbres erosionadas tiempo atrás. Las técnicas de aterrazamiento son impresionantes en las grandes montañas del mundo (poblados del Tibet y Nepal, pueblos precolombinos de los Andes, etc.) y tienen magníficas reproducciones a escala en nuestras montañas (Serranías de Levante, Pirineos). Con estos muretes se procuraba conseguir llanos arables en laderas pendientes; el pueblo de montaña obtenía cultivos de llanura a base de construir sus propios llanos. Estos esfuerzos sólo tuvieron sentido cuando las horas dedicadas al cereal no contaban y lo único importante era tener pan que comer. Cuando el montañés consigue fácilmente grano excedente de los llanos vecinos desarrolla otras formas de explotación más adecuadas a las zonas pendientes, conserva algunos patatares como regulador importante y convierte gran parte de sus campos de cereal en prado de siega. "Ya no trabaja más la tierra" y deja que se invada de hierba para los animales.

$$
* * *
$$

En los apartados que siguen resumiré algunas reflexiones obtenidas de las montañas de Huesca y procuraré presentarlas bajo este enfoque de retención de fertilidad en cotas altas mendiante las formas de explotación ganadera tradicional. 


\section{Los rumiantes como aceleradores de la incorporación de fertilizantes al suelo.}

Resulta interesante recorrer los pastos de verano de nuestras montañas tras la fusión de la nieve y antes de iniciarse un nuevo ciclo productivo. Puede comprobarse que los restos secos no comidos el año anterior siguen con sus tallos al aire, más o menos quebrados por el peso de la cubierta de nieve que soportaron, pero sin trazas de descomposición importante. Sin embargo, las boñigas depositadas en una zona vecina, bien pastada, difícilmente conservan su forma original y aparecen rotas en pequeños fragmentos con variados estados de incorporación al suelo. Se trata de restos "con energía", en los que se han desarrollado multitud de larvas que erosionaron y trituraron el material más grosero. Las bacterias, que habian iniciado su trabajo en la panza caliente del rumiante, se incorporan como finos cadáveres ricos en minerales y más difíciles de arrastrar que un simple catión de los complejos químicos. En esos depósitos buscó y comió insectos la chova de los pastos pirenáicos y con sus patas y pico rasgó la cubierta endurecida de la boñiga vieja facilitando una mayor aireación.

Comparando los ciclos de incorporación al suelo seguidos por el resto seco y la boñiga, comprendemos fácilmente la función aceleradora ejercida por la vaca en pastoreo. Aún más exagerada resulta la deposición de la oveja dividada ya convenientemente por el animal en diminutas cagarrutas y repartida ampliamente en las zonas pastadas. Una posición intermedia ocuparía el caballo.

El ganadero comprendió rápidamente la importancia de estos restos elaborados por los animales y los utilizó durante años como complemento de sus parcelas agrícolas. Esta fase de explotación del animal productor de estiércol ha llegado hasta nuestras montañas mediante las tradicionales técnicas del redileo. Después hemos visto cambiar las parcelas de cereal a prado, pero subsisten los encierros móviles que concentran fertilidad en los prados pendientes. El ganadero desplaza las vallas que encierran a sus ovejas y así no tiene que mover estiércol; es una técnica aceptable cuando se crían animales en pastoreo permanente, sin confinamiento en el establo. Al progresar la estabulación estacional, se acumula el producto de varios meses y nacen los estercoleros como depósito de la preciada mercancía. Estamos ya en una fase de "cosecha", con elementos fertilizantes concentrados cerca de los cultivos más exi- 
gentes y no siendo necesaria la recolección de boñigas en los pastos recorridos libremente por los animales en pastoreo. Tras la estabulación, el ganadero reparte en sus prados el estiércol almacenado y lo distribuye de acuerdo con el programa que tiene planteado, cerrando un ciclo anual en el que hay grandes pérdidas de estiércol hacia el valle.

El reparto de estiércol por los animales en pastoreo: sus características en puerto

Las vacadas actuales que pastan puertos de verano en la mayoría de los municipios de montaña de la provincia de Huesca lo hacen bastante libremente, con pautas de comportamiento que recuerdan sus antiguos desplazamientos en manada. Por ello se observa la influencia del estiércol sobre las zonas más favorecidas por el pastoreo y con ella se puede elaborar una clasificación de las masas homogéneas distinguibles en estos pastos.

\section{La ocupación de cumbres y salientes venteados}

Los días calurosos de agosto las vacas buscan defensa en las cumbres batidas por el viento y en los salientes que reciben mejor la brisa del valle. En ambos casos consiguen diferencias de unos $5^{\circ} \mathrm{C}$ por debajo de la temperatura normal del pasto vecino y pueden mantener una actividad aceptable de rabo, orejas y cabeza para luchar contra las moscas que les acechan continuamente. Allí pasan la mayor parte del día y no inician el pastoreo de la tarde hasta que disminuye el calor. Se trata por lo tanto de unos lugares que día tras día reciben una estercoladura importante, pero observemos con atención alguna de sus características.

Las cumbres pastadas de los montes de Ansó y Hecho (Alto Aragón occidental) rondan $10 \mathrm{~s} 2300 \mathrm{~m}$ y las recorren en pleno verano los rebaños de ovino. Se trata de zonas muy influidas por la nieve, donde la estación vegetativa no va más allá de los tres meses y medio (julio-mediados de octubre). En este corto período las plantas deben efectuar un crecimiento suficiente para desarrollar sus órganos reproductores y asegurar la nueva generación. En el suelo, el crecimiento de las raíces ha de ser suficiente para alargarlas hasta horizontes profundos en los que se puedan afianzar eficazmente 


\section{GANADERIA Y PERDIDA DE FERTILIDAD EN MONTAÑA}

contra el descalce del hielo-deshielo. Ambos factores, clima duro y erosión provocada por el hielo, son mucho más importantes que el efecto beneficioso ocasionado por el estiércol de oveja depositado en los días de sesteo. Se tratará por ello de una vegetación "salvaje", más adaptada al rigor de las cumbres y poco preparada para beneficiar la estercoladura recibida.

Los salientes venteados son puntos topográficamente favorecidos en cuanto a su exposición al viento y se localizan en cualquier ladera que bordee los fondos glaciares de estas zonas. Por ello su altitud es más baja que la de las cumbres y el ciclo vegetativo se alarga un mes más (desde principios de junio) con escasa incidencia de los fenómenos de hielo-deshielo. En estos lugares los animales que no pueden alcanzar la cumbre, pasan las horas de calor $y$ efectúan un aporte de boñigas incorporado eficazmente al suelo. La discontinuidad creada en estos islotes es muy aparente y se puede juzgar desde distintos aspectos: por lo que se refiere a las plantas vemos especies que ya responden eficazmente al abonado y que normalmente no entrarían en los restos del pasto. Entre éstas hay algunas que desarrollan abundantes bulbillos y tubérculos siendo muy apreciadas por el jabalí. Se juntan por tanto en esos pequeños salientes dos de las características agrícolas que después, en cotas más bajas, practica ampliamente el agricultor; se trata del laboreo y abonado con estiércol. El jabalí levanta activamente la cubierta de pasto y rompe el césped dejando la tierra desnuda donde crecerán fácilmente las "patatitas". Es un cultivo anual que repiten los jabalíes al frecuentar estas laderas desde la primavera. Es difícil deslindar la causa y el efecto, pero lo cierto es que la relación tubérculojabalí se desencadena con el estiércol depositado por la vaca en pastoreo. En estos lugares consiguen crecer plantas que normalmente no alcanzarían esas cotas y son animales los que "suben" fertilidad en contra de la gravedad, manteniendo unos ciclos vegetativos más productivos.

\section{Las majadas como límites de contaminación}

La intervención del hombre en estos puertos de montaña se apoya en un pequeño refugio con cabaña y área para los animales. En el caso de las ovejas, es el lugar en el que pasan la noche al aire libre y donde se encuentran seguras al cuidado del pastor y sus perros. Pero las vacas solían poseer además una pequeña valla de 
piedra que impedía la salida nocturna de animales. En la actualidad ya no se reunen cada noche en la majada, pero las vacas han mantenido ese hábito de acercarse a la caseta del vaquero donde pueden recibir una dosis de sal o son curadas con los tratamientos que aplica el ganadero desde su caseta. Hay por tanto una acumulación de fertilidad ocasionada por tratarse de la zona de contacto entre hombre y animal. La vegetación se convierte en plantas de gran porte y con hojas ricas en sales, únicas capaces de retener en forma de estructura vegetal los nutrientes que podrían ser lavados antes de incorporarse al suelo.

La existencia secular de majadas ha permitido la subida a cotas altas de plantas capaces de inmovilizar sales y soltarlas lentamente, bien en forma de alimento para los animales bien en forma de restos secos. En tiempos de funcionamiento completo del sistema pastoral, las muchas ortigas que crecen en estos lugares eran comidas con avidez por los cerdos que acompañaban al pastor-quesero $\mathrm{y}$ complementaban así la dieta proporcionada por el suero sobrante de la fabricación del queso. En la actualidad, las ortigas son menos dominados por las vacas de la majada y se acumulan exageradamente en los rincones rocosos menos frecuentados. Cuando el exceso de estiércol dificulta el crecimiento vegetal, se amontona en forma de producto contaminante y es lavado por la lluvia hacia cotas más bajas. Con la situación actual de falta de cerdos se observa la importancia de una buena localización de la majada en cada ladera para convertirla en un distribuidor de fertilidad hacia las zonas vecinas. Aún no existen canalizaciones para repartir estiércol mediante agua, pero es una posibilidad ampliamente practicada en los Alpes.

En resumen, podemos asimilar las majadas a unas zonas de amortiguamiento en cuanto a la pérdida de fertilidad por gravedad, unos reductos en los que crecen plantas capaces de inmovilizar los fertilizantes en cotas elevadas para favorecer su reutilización como minerales que serían contaminantes al descender súbitamente aguas abajo.

Explicadas las características anteriores, podemos hacer una primera clasificación de las grandes superficies de pastoreo según el grado de actuación de los animales. Unas no se verán influidas por los herbívoros domésticos y funcionarán a ritmo lento, con estructuras muertas incorporadas al suelo en forma de pequeñas producciones anuales. Otras, las más comidas, se especializan en ser grandes exportadoras de minerales hacia el animal, acelerando sus propios ciclos productivos. Finalmente, las que soportan un aporte 
GANADERIA Y PERDIDA DE FERTILIDAD EN MONTAÑA

exagerado de estiércol lo acumulan en amplias hojas ricas en sales que después se descompondrán lentamente. Por lo tanto, la perturbación ocasionada por la carga ganadera es parcialmente retenida en forma de pastos especializados para los distintos grados de contaminación.

\section{Los buitres como última posibilidad de retener los cadáveres}

Cada año mueren algunos cientos de animales en los pastos de1 Pirineo y sus cadáveres llegan en forma de blancos huesos repartidos por las riberas de los principales ríos. Cualquier pescador de montaña puede observar restos de costillas, caderas, algun fémur y tibia trabados entre las piedras que salta al ir lanzando el cebo. Se trata de los restos más pesados, los que no hay manera de retener en las laderas en que cayeron muertos los animales. Sin embargo, el resto del cuerpo quedó en las alturas en forma de nuevas crías de buitre y muchos miles de moscas.

El pastoreo en laderas difíciles ejerce una fuerte presión de selección sobre animales enfermos y poco adaptados a cambios bruscos. Las variaciones de clima, dieta o problemas de parto ocasionan bajas entre las ovejas y vacas del puerto y sus cadáveres caen sin remedio en el lugar del ataque o del accidente. En esos instantes se pone en funcionamiento un sistema de recuperación de nutrientes que tiene gran parecido con el explicado para las boñigas. Si en la zona existe una colonia importante de buitres ella se encargará de incorporar rápidamente aquellas carroñas en forma de nuevas crías. Su trabajo de vaciado acelera enormemente la putrefacción de los restos no comidos y en ellos hacen su puesta multitud de moscas que llenarán de larvas el cadáver. De ahí nacerán nuevos insectos adultos que, muy a pesar de vacas y ovejas, seguirán revoloteando por el puerto. De esta forma, la labor del buitre permite un rápido aprovechamiento del animal muerto y protege gran parte del cuerpo contra el arrastre inexorable de las masas de nieve en fusión. Los huesos que no fueron rotos por el solitario quebrantahuesos ni comidos por zorros y perros, serán arrastrados la primavera siguiente ladera abajo escapando así a su mineralización en el puerto.

La correlación entre zonas de pastoreo y colonias de buitres es tan estrecha como la existente entre el estiércol y el escarabajo pelotero, o la explicada de las plantas de majada. Es un factor más a 


\section{FEDERICO FILLAT ESTAQUE}

tener en cuenta en la lucha contra la gravedad y se debe tratar de un mecanismo de aprovechamiento mineral desarrollado ya con proliferación de los hervíboros.

\section{Algunas características fundamentales de la explotación en montaña}

Hemos explicado la acción importante contra la erosión practicada en los aterrazamientos para producir cereal pero además de esta lucha diaria por el sustento, el montañés realiza constantemente otras acciones que contribuyen a mantener nutrientes y energía en las cotas altas.

\section{Los desplazamientos en montaña}

E1 hombre primitivo que habitó las montañas en contacto directo con los animales salvajes copió eficazmente los desplazamientos ya probados por el oso, lobos, zorros, jabalí y venados. Para cambiar de valle es evidente que las cotas más bajas y por tanto menos penosas son los collados. La mayoría de los existentes en el Pirineo fueron bautizados por las generaciones pasadas, lo que muestra su amplio uso y conocimiento. En las subidas por cada ladera se procura vencer el desnivel cambiando suavemente de cota con abundantes zigzagueos que eviten el enfrentamiento directo entre viandante y cuesta. Cuando es imprescindible atravesar una zona boscosa los trayectos más practicados son los que evitan la completa penetración en el bosque, siguiendo sendas de divisoria de agua o fondos de valle. En ambos casos podían evitarse los imprevistos que sufriría a diario el montañés al internarse en sus bosques-selva. Por los ríos transportó las mercancías más pesadas que podía exportar, los troncos de sus bosques, y utilizó ampliamente sus riberas con rápidas sendas.

Históricamente, cuando las comunidades de montaña entran en conflicto con otras del valle o de tierras lejanas, demuestran la eficacia de sus conocimientos. Para los romanos resultó imposible adentrarse en los Montes Cantábricos y los ejércitos de Carlomagno lo pasaron mal en el Pirineo navarro. En los primeros años del pireneismo contrastaba el complejo equipo del alpinista con la somera indumentaria del montañés $y$, en el admirado Parque de Ordesa, 
el herrero de Torla dejó constancia de su valor colocando "las clavijas" que aún perduran para uso del excursionista sin vértigo.

En el aspecto ganadero, cuando tiene que optar entre transportar estiércol o conducir animales en trashumancia de bordà en borda, elige esta segunda alternativa y construye nuevos establos en las parcelas que va convirtiendo en prados. De este modo, el fertilizante y la parcela que tiene que abonar se reunen en un mismo lugar, sin necesidad de gastos en transporte. Ya dentro de la parcela, reproduce a pequeña escala los conocimientos que practica en las grandes laderas. Así, la recogida de heno y el reparto de estiércol se hacen siguiendo estudiadas curvas de nivel que permiten una acción eficaz sobre la parcela con el mínimo esfuerzo. En caso de superproducción de hierba sin henil previsto, se guarda en el mismo prado mediante la confección de un "pajar" de intemperie al que irán a comer los animales cuando se haya acabado la cosecha del henil cubierto.

\section{El ritmo de aprovechamiento de pastos de verano}

E1 pastoreo desde las cotas bajas (unos $1200 \mathrm{~m}$. en el Alto Aragón occidental) hacia las cumbres, consiste en un itinerario que pretende restituir fertilidad subiéndola con el desplazamiento de los propios animales. Así se puede comprender la inquietud de aquel pastor que pretendía conducir una treintena de ovejas a una faja de pasto colgada entre paredones de caliza; decía que había que comer aquella hierba, pero en el fondo sabía que se repartiría por la ladera el estiércol allí depositado. En esa misma línea, y casi inconscientemente, el vaquero obliga a los animales a permanecer en las laderas más empinadas cuando hay comida y no amenaza el mal tiempo.

La entrada en las unidades de pastoreo se hace cuando la fusión de la nieve está avanzada y las temperaturas permiten un crecimiento adecuado de la hierba. Se produce, por lo tanto, una distribución de fertilidad en altitud condicionada por los factores climáticos. El ganadero lucha contra la pendiente y el rigor de la montaña procurando colonizar con sus animales en pastoreo hasta las cumbres más difíciles, para ensanchar de ese modo el área potencial de pastoreo.

La estructura ganadera necesaria para explotar las diversas posibilidades de fertilidad en cada ladera fue tradicionalmente muy completa y comprendía rebaños de cabras, borregos-carneros, ovejas madres, vacas, yeguas y algunos corderos. Ya quedó explicada la rela- 
ción del cerdo con los mejores pastos de majada y no resulta difícil comprender que en el otro extremo, en el límite ya con los rebaños salvajes, se encuentra la cabra. Se trata, por lo tanto de una gradación que engloba conceptos de domesticación y de peso; así el cerdo, con los abundantes jamones que la selección ganadera fomentó en sus extremidades posteriores, no se parece ya al nerviosos jabalí, de amplia capacidad respiratoria, y debe permanecer en el lugar más humanizado del puerto. La cabra se resiste a una domesticación intensa y sus hábitos de pastoreo le proporcionan suficientes recursos para escapar de los peñascales más difíciles en los que pastó a placer. De la oveja se explota hábilmente su poco peso haciéndola encaramar por laderas muy pendientes donde no es posible mantener a la vaca. Sin embargo, el pesado vacuno y las yeguas resultan imprescindibles para dominar un pasto alto en el que la oveja se perdería sin posibilidad de comerlo. Con este planteamiento se comprende que la oveja pueda seguir las zonas pastadas por vacas, apurando al máximo los tallos que no alcanzó a cortar la vaca; por ello suben más tarde y bajan detrás de las vacas.

En resumen, los rigores del clima no fueron obstáculo para que el ganadero esperase el momento oportuno de subir hasta el pie de los últimos neveros con sus rebaños y organizase pequeñas praderas con el estiércol allí depositado por los animales. La estructura ganadera fue diversa y algunos se decidieron por ovejas mientras otros lo hacían por yeguas o vacas, formando un conjunto ganadero equilibrado con el que explotaban los diversos tipos de pasto surgidos del aporte de estiércol y de las condiciones topográficas.

\section{El paisaje ganadero de los alrededores del pueblo}

En las montañas españolas todos los asentamientos humanos nacieron en zonas que habían sido bosques y fue necesario talar los árboles para iniciar cultivos panificables. Los bosques con buena exposición solana se transformaron en campos de mijo y trigo sarraceno pasándose después a los granos más gordos de maíz y trigo. Por ser cultivos de año y vez suministraban abundante rastrojo en los que se practicaba el derecho de derrota con los ovinos. Para los animales de labor se reservaban los boalares o los sotos y no existía, en ambos casos, un esfuerzo deliberado del agricultor para conseguir parcelas de pasto mediante siembra. Con la patata de América 


\section{GANADERIA Y PERDIDA DE FERTILIDAD EN MONTAÑA}

se enriqueció la dieta del montañés y después algunos patatares pasaron fácilmente a cultivos forrajeros. Hace unos treinta años que nuestras montañas cambiaron su fisonomía cerealista por los actuales prados y cultivos forrajeros.

La trayectoria explicada condicionó fuertemente la recuperación del bosque y sólo quedan verdaderas masas forestales en las umbrías más recónditas donde no se cultivó el cereal. Los antiguos campos habían sido labrados en situaciones muy diversas, explotando laderas poco productivas los últimos cultivadores incorporados al término municipal, porque cada valle pertenecía a familias arraigadas desde antiguo en el lugar. Veamos cómo en estas cotas bajas, cercanas a las casas, se reproducen los rasgos explicados anteriormente para el paisaje "salvaje" de los puertos de verano.

\section{Las parcelas de plena propiedad}

Se trataba de las antiguas tierras adquiridas por los particulares a partir de la propiedad real o de los dominios del señor correspondiente. Su completa privatización es reciente, ya que hasta finales del siglo pasado se seguía practicando el antiguo derecho de derrota que había adquirido la nueva expresión de "derecho de primera hierba". Ello suponía que perduraba la servidumbre hacia la comunidad con sólo el derecho de aprovechar la primera cosecha pasando el rastrojo o el rebrote a uso comunal. Cuando se pudieron vallar las parcelas y progresó la estabulación, resultaba rentable esparcir estiércol para aumentar la hierba que engordaría el ganado del propietario. Abonado y riego conviertieron los recintos en prados productivos que, en cierto modo, imitaban las majadas del monte. Si el riego era copioso se podía conseguir un segundo corte aceptable y aún sobraba fertilidad para un crecimiento otoñal o rebasto aprovechado en pastoreo. En estos prados se aplica toda la experiencia acumulada por siglos de cultivo ceralista y tanto el guadañado como las técnicas de henificación concuerdan directamente con las practicadas en los antiguos campos. Eran por cierto el lugar ideal para invertir gran esfuerzo en mano de obra y el más apto para unos animales productivos, de rápido crecimiento.

\section{Los antiguos escalios}

Parte de la propiedad comunal fue roturada directamente por 


\section{FEDERICO FILLAT ESTAQUE}

particulares que sólo tenían el derecho de cosecha mientras cultivasen la parcela roturada. En caso de abandono se volvían a incorporar al común. Cambios posteriores permitieron pasar algunas de estas parcelas a la propiedad privada y son ahora prados alejados del núcleo habitado. En estos lugares con buenas condiciones topográficas pero sin posibilidad para el transporte de estiércol ni de regar en buenas condiciones, el ciclo anual no permite los dos cortes del prado del pueblo y se pierde el rebrote. Sus homólogos "salvajes" podrían ser los salientes venteados donde se conseguía una productividad alta respecto al pasto uniforme de la ladera. La extracción del primer corte de hierba se compensa aquí con un somero aporte de estiércol subido desde las cuadras del llano y mediante una otoñada prolongada de pastoreo. Aquí ya no compensa desplazar animales muy selectos que pierden energía en el transporte y no valoran suficientemente el poco pasto existente. Se trata por lo tanto de zonas aptas para razas o animales poco exigentes.

La gama ganadera explicada para el aprovechamiento completo de los puertos de verano presenta caracteristicas parecidas en los alrededores del pueblo. Además, en el pueblo se pueden reservar unas pocas zonas muy productivas donde alimentar a algunos animales que no precisen subir a puerto, con ciclo anual suficientemente rentable pero muy exigentes en mano de obra. Estas posibilidades ya se han ensayado con la introducción reciente de la vaca Frisona en algunos valles con buenas propiedades, sin embargo la explotación del término municipal completo no podría continuar si todos los ganaderos adoptaran esta dedicación lechera tan intensiva.

\section{Algunas generalizaciones sobre complementariedades regionales}

El esquema de montaña ganadera expuesto hasta aquí sólo se pudo completar sin salir del término cuando los recursos fueron suficientes para soportar el largo invierno. En la mayoría de los valles se practicaba la trashumancia buscando en la Ribera o en el Prepirineo los complementos alimenticios que no proporcionaba el término propio. En la actualidad muchas explotaciones de montaña siguen produciendo gracias a unas importaciones masivas de alfalfa y harina compradas en el llano a precio de mercado; en el fondo, ha sido una evolución que olvida todos los principios del 
transporte de la fertilidad a bajo coste; se produce de forma desordenada jugando únicamente con el mercado como regulador $\mathbf{y}$ puede tratarse de una opción difícil de corregir. Si observamos atentamente algunas estrategias del ganadero tradicional comprenderemos mejor los peligros inherentes a cualquier intensificación masiva.

En el pastoreo de los puertos quedó claro que se acumula fertilidad en las majadas y sólo podemos retenerla en cotas altas para reciclar varias veces si tenemos plantas capaces de acumular una sobredosis de sales. Sin majadas, cada zona de pastoreo en pendiente mandaría anualmente toneladas de estiércol a los ríos del valle empobreciéndose la hierba y contaminándose los pueblos. Sin buitres las carroñas bajarían fácilmente al río cercano y no se podrían convertir en nuevos nutrientes. Ya en la cota de los pueblos ganaderos, el estiércol acumulado durante la estabulación invernal proporciona nuevos rebrotes al prado y no se pierde en los ríos y torrentes que pasan por el pueblo. Es un bonito modelo en cascada con peldaños que procuran retener el agua y los fertilizantes transportados efectuando sucesivos reciclados en una cota cada vez más baja. La energía potencial se va perdiendo sin saltos bruscos, sin discontinuidades contaminantes, y es aprovechada eficazmente mediante unas estructuras ganaderas diversificadas.

De una forma menos aparente encontramos en cualquier cuenca hidrográfica más amplia este modelo montañés de aprovechamiento de nutrientes contra la fuerza de la gravedad, que tiende a bajarlos rápidamente hacia los llanos vecinos. A escala comarcal se puede reproducir el esquema y con ello cada producto aumentaría su valor añadido al aproximarse al final de la cuenca, a la comarca del llano más rica en suelos profundos y sin las limitaciones de información en cuanto a mercados. Si estos saltos del producto se hacen casi de vecino a vecino minimizamos el transporte y así no progresa la contaminación ya que el control de las disfunciones resulta inmediato. Con este sencillo esquema resultaría evidente que cualquier granja de engorde debería ir emparejada con el sistema recuperador de fertilidad correspondiente; así no se plantearía la siembra de praderas muy exigentes en nutrientes a costa de transportarlos desde otros lugares muy alejados. El agua podría llegar limpia a las poblaciones del llano sin grandes esfuerzos en la policía de aguas.

Esta ganadería bien situada tiene sus equivalentes en el sector industrial o en el turístico. En conjunto, el sencillo fenómeno de la gota de agua que cae y baja paulatinamente no se ha planteado todavía como un esquema básico de organización. 